
History Research

Reseña

\section{Raimon Soler-Becerro. Viticultura, desigualtat i conflicte agrari. La lluita per la terra a la Catalunya vitícola, 1900- 1936. Tarragona, Vilafranca del Penedès, Publicacions URV, Vinseum, 2019, 301 pp. ISBN: 978-8484247357.}

El trabajo de Raimon Soler-Becerro tiene como principal objetivo mostrar la relación entre desigualdad y conflicto agrario en la Cataluña vitícola durante el período 1900-1936, años en los que acabaría estallando con toda su crudeza. Para ello analiza de manera pertinente y rigurosa el contexto y los factores que considera clave en su desarrollo, utilizando un buen abanico de fuentes de diversa índole (de carácter fiscal, censos electorales y padrones municipales, archivos patrimoniales, documentación de sindicatos agrícolas, expedientes electorales, prensa local, etc.).

Partiendo del estudio pionero del conflicto rabasaire de Giralt Raventós (1964) y recogiendo aportaciones más recientes, como la de Planas y Valls-Junyent (2012), sobre la relación entre desigualdad, asociacionismo y conflictividad, se propone ahondar en esta relación poniendo el foco en el Penedés, la zona donde el movimiento social agrario de los años treinta fue más intenso.

Tras un primer capítulo introductorio, analiza las dificultades por las que atravesó el sector vitícola catalán en el primer tercio del siglo $\mathrm{xx}$, las cuales debieron comportar el aumento de las desigualdades y de las tensiones entre capital y trabajo. Mientras se replantaban las vides afectadas por la filoxera, Francia limitaba las importaciones de vino, a la vez que aparecían nuevos competidores, especialmente en América del Sur. Al estallido de la Primera Guerra Mundial (con el aumento de los costes de producción que generó), la ley seca en Estados Unidos (1920-1933) y las medidas proteccionistas aplicadas en Francia a partir de 1930, se añadirán otros problemas internos, como la mala calidad de los caldos y el impuesto de consumos que grababa especialmente el vino. Todos estos factores generaron sucesivas crisis de sobreproducción que no consiguieron acabar, sin embargo, con el gran peso relativo del sector vitivinícola en la agricultura y economía catalanas.

En este marco se produjo el conflicto rabasaire, de gran trascendencia en la Segunda República. En un enfrentamiento cuyas raíces hay que buscar en la segunda mitad del siglo xvII, rabasaires y propietarios intensificaron sus esfuerzos para llevar a su terreno los derechos sobre las cepas y la tierra. Como señala el autor, la conflictividad se originó precisamente en torno al principal instrumento jurídico que había favorecido la expansión de la vid en Cataluña -el contrato de rabassa morta-, constatando la existencia de una relación positiva entre la importancia de la viticultura en cada distrito y la intensidad del conflicto. Sin embargo, no en todas las comarcas vitícolas en conflicto tuvo la misma fuerza. ¿Qué explica esta diferencia? ¿Por qué el Penedés se convirtió en el epicentro del con- flicto agrario? Los factores que pudieron entrar en juego serían la estructura de la propiedad; la importancia de la gran propiedad en el régimen de explotación; las características de las pequeñas explotaciones familiares, y la articulación de comunidades de campesinos capaces de gestar fuertes lazos de solidaridad que facilitarían la acción colectiva. Así, desde la concepción de movimiento social de Tilly y Wood (2010), en los dos últimos capítulos se analizan la organización y el repertorio del movimiento rabasaire, es decir, la acción colectiva a través de los sindicatos y el cooperativismo, así como la movilización electoral como otra vía para conseguir sus fines.

En el Penedés, la replantación de cepas tras la filoxera fue más intensa y rápida que en otras zonas vitícolas, lo que supuso un aumento de la dependencia de muchos agricultores respecto a un cultivo que había comenzado a ser poco remunerador desde la Primera Guerra Mundial. Y, a diferencia de lo que ocurría en áreas cercanas, como la provincia de Tarragona, buena parte de la riqueza rústica estaba en manos de unos pocos grandes propietarios, cuya tipología y perfiles son analizados en detalle. A la hora de gestionar sus patrimonios, optaban por ceder la explotación de las tierras a rabassa morta y aparcería, ya que resultaba más barato y conveniente que el trabajo asalariado. Los cultivadores, por su parte, explotaban pequeñas parcelas, muy pocas veces en propiedad, y mayoritariamente a través de estos contratos agrarios, con resultados a menudo insuficientes para garantizar la reproducción de la unidad familiar. Tendríamos aquí, por tanto, unos factores -aunque no los únicos-que ayudarían a explicar por qué en esta zona el conflicto fue más virulento que en otras áreas vitícolas: había relativamente pocos propietarios, con mucha tierra, y muchos rabasaires, con muy poca. Analizando las demandas de revisión de contratos que los trabajadores presentaron en 1932 en cada distrito, demuestra que cuanto mayor era la concentración de la propiedad, mayor era también el número de demandas, es decir, más intenso era el conflicto.

Tras la filoxera, los rabasaires habían asistido a la desaparición o desnaturalización de sus antiguos contratos, que tradicionalmente se habían considerado vigentes hasta la muerte de las cepas, convirtiéndose en aparceros o arrendatarios a partes de frutos. La mayor parte de sus explotaciones -como muestra Soler-Becerro- no eran suficientes para garantizar el mantenimiento de las familias ya que, en conjunto, tenían una dimensión media de 4,4 ha. Teniendo en cuenta que en el Penedés se ha estimado que eran necesarias al menos 5,9 ha para la reproducción de la unidad doméstica, se explica la necesidad de recurrir a actividades complementarias (como el trabajo en fábricas allí donde las había o la cría y venta de cerdos, conejos y gallinas, muchas veces por parte de las mujeres de la casa). El análisis que el autor lleva a cabo sobre las profesiones, la contribución rústica y las tarifas de las cédulas personales, indica que precisamente fueron los sectores con rentas más 
bajas, especialmente los que no disponían de tierras en propiedad, los que se movilizaron con más intensidad.

La existencia de fuertes lazos de solidaridad entre los rabasaires estuvo en la base de la movilización colectiva y dio lugar a la creación de diversas formas de organización, entre las que destacó la Unió de Rabassaires, que vivió una fuerte expansión durante la Segunda República. Por otra parte, a las acciones de resistencia de tipo tradicional se añadieron algunas nuevas como las demandas de revisión de renta de sus contratos, campañas en las que participaron miles de familias (en 1934 se presentaron más de 10000,24 por cada 100 habitantes, en el partido judicial de Vilafranca), al mismo tiempo que retenían las partes de fruto tocantes a los propietarios. Aborda también el papel de las cooperativas en las pequeñas comunidades campesinas, con unas funciones importantes de economía social (obtención de inputs y artículos de consumo), además de la creación de secciones de ocio o de mutualidades que favorecían la cohesión de la comunidad.

Otra de las formas de acción colectiva que incorporó el movimiento rabasaire fue la intervención en la política formal. Los rabasaires se vincularon pronto al republicanismo, teniendo a Lluís Companys como referente y apoyando a Esquerra Republicana en las convocatorias electorales entre 1931 y 1936. Con una gran capacidad de movilización e influencia en el ámbito local, consideraban que las urnas debían servir para demostrar su fuerza y exigir a los dirigentes políticos que cumpliesen con las expectativas que habían generado.

La Guerra Civil y su resultado supuso una fractura que daría un lugar a una realidad completamente nueva. Durante la contienda, los rabasaires se apropiaron de la tierra que trabajaban, formaron federaciones cooperativas e intentaron contribuir con su trabajo -y a veces con sus vidas- al esfuerzo de guerra. Una vez acabada, la represión fue feroz con algunos líderes rabasaires y los sindicatos agrícolas, que tanto habían fortalecido las redes de solidaridad, fueron clausurados.

No es tarea fácil radiografiar -económica, social y políticamente- a los agentes protagonistas de un movimiento social, así como al conflicto mismo. Y es eso precisamente lo que Raimon Soler-Becerro consigue en esta obra. En sus páginas, la relación entre desigualdad y conflictividad no solo se intuye, sino que aflora como resultado del análisis riguroso de fuentes de diversa índole y una metodología acertada. Los agitados años treinta, con sus convulsiones de todo tipo, fueron escenario del movimiento social agrario más importante en Cataluña, que aquí queda retratado en toda su complejidad.

Belén Moreno Claverías

Universidad Autónoma de Madrid

https://doi.org/10.33231/j.ihe.2020.12.009 